\title{
Prevalence of asthma, atopy, and bronchial hyperreactivity in bronchiectasis: a controlled study
}

\author{
J PANG, H S CHAN, J Y SUNG \\ From the Department of Medicine, Chinese University of Hong Kong, Prince of Wales Hospital, Shatin, \\ Hong Kong
}

ABSTRACT The prevalence of atopic diseases and bronchial reactivity to histamine and methacholine $\overrightarrow{\vec{o}}$ was determined in 36 patients with bronchiectasis and in 36 control patients matched for age, sex, and $\stackrel{\infty}{\infty}$ smoking history. There was no difference in the prevalence of asthma, other atopic diseases, family 9 history of atopic diseases, or positive responses to skinprick tests (nine versus five) in the two groups. $\overrightarrow{-}$ The prevalence of bronchial hyperreactivity, however, was significantly higher in the group witho bronchiectasis than in the control group for both histamine ( $7 v 0$ patients) and methacholine $(6 v 0 \infty$ patients). The group with bronchiectasis had more airflow obstruction (mean FEV $167 \%$ predicted), $\frac{3}{\circ}$ but there was no correlation between spirometric indices and $\log \mathrm{PD}_{20}$ (the $\log$ dose of histamine or $\stackrel{\mathbb{D}}{-}$ methacholine causing a $20 \%$ fall in $\mathrm{FEV}_{1}$ ). This suggests that, although reduced airway calibre may $\overrightarrow{0}$ be a factor underlying bronchial hyperreactivity in bronchiectasis, it is not the only mechanism.. Further studies are needed to determine whether bronchial hyperreactivity has a causative role in the pathogenesis of bronchiectasis or whether it occurs as a result of the disease.

\section{Introduction}

Asthma and bronchial hyperreactivity may play a part in the aetiology and pathogenesis of bronchiectasis by reducing the efficacy of respiratory clearance mechanisms and thereby promoting microbial colonisation and inflammation. ${ }^{1}$ This hypothesis is supported by studies that show an apparently high prevalence of atopic diseases, including asthma ${ }^{23}$ and bronchial hyperreactivity, ${ }^{2-4}$ in patients with bronchiectasis. These studies, however, either were uncontrolled ${ }^{23}$ or used a small number of poorly matched subjects. ${ }^{4}$ Using an equal number of age and sex matched normal subjects, Murphy et al ${ }^{5}$ found no significant increase in the prevalence of atopy in 23 patients with bronchiectasis. Bronchial reactivity was not measured, however, and they did not control for cigarette smoking, a factor that may affect the prevalence of both atopy ${ }^{67}$ and bronchial reactivity. ${ }^{89}$

In view of the conflicting results and paucity of comparative data in well matched control subjects, we

Address for reprint requests: Dr J Pang, Department of Medicine, Chinese University of Hong Kong, Prince of Wales Hospital, Shatin, NT, Hong Kong.

Accepted 12 July 1989 have studied the prevalence of atopy and bronchial $\vec{P}$ hyperreactivity in 36 patients with bronchiectasis and 3 in 36 control patients matched for age, sex, and smoking history.

\section{Methods}

PATIENTS

The study group consisted of 36 patients with bron- $-\frac{3}{3}$. chiectasis whose clinical diagnosis was confirmed by 8 computed tomography with bronchography when $₹$ necessary. None of the patients had cystic fibrosis, 9 bronchopulmonary aspergillosis, or humoral immune deficiency; there was no attempt to select the patients by any other criterion. The mean duration of respiratory symptoms was $10 \cdot 7$ (SD 8.5, range 1-40) years.. The extent of disease on the computed tomogram was 0 estimated by dividing each lung into upper, middle, $\mathbb{W}^{2}$ and lower zones (total six zones). The mean number of 0 zones affected by bronchiectasis was 2.5 (SD 1.3, range 1-5).

The control group consisted of 36 patients matched $\stackrel{\Phi}{\oplus}$ for age, sex, and smoking history (to within five pack 0 years). They were selected from orthopaedic and $\overline{0}$ gynaecological patients awaiting elective surgery. $\stackrel{\overrightarrow{\mathrm{D}}}{\stackrel{\mathrm{Q}}{\mathrm{Q}}}$ None had any evidence of lung disease or infection. त Informed consent was obtained from all patients. 


\section{QUESTIONNAIRE}

A respiratory questionnaire was given to all patients to obtain information on chest symptoms, smoking history, and any personal or family history of atopic diseases. These included asthma, allergic rhinitis, eczema, urticaria, angioneurotic oedema, and contact dermatitis. For the diagnosis of asthma a history of dyspnoea, wheeze, or coughing that varied spontaneously or occurred after exposure to known precipitating factors was considered significant, especially if there was nocturnal exacerbation. In doubtful cases home peak flow monitoring was carried out. A patient was considered to have a history of atopy if he had one or more of the above diseases, and to have a family history if a first degree relative had one or more of the above diseases.

\section{INVESTIGATIONS}

All patients were studied when they were clinically stable and had been free from acute respiratory infections for at least two months. After a physical examination the following investigations were performed: posteroanterior chest radiography, skinprick tests, spirometry, and measurement of bronchial reactivity to histamine and methacholine. Skinprick tests were carried out with 12 commercially available reagents (Bencard): diluent control, house dust, Dermatophagoides pteronyssinus, Dermatophagoides farinae, dog hair, cat fur, grass pollen, Aspergillus fumigatus, Aspergillus niger, Cladosporium herbarum, Penicillium spp, and Pullularia pullulans. The responses were read at 15 minutes and considered positive if the mean weal diameter was $2 \mathrm{~mm}$ or more in the presence of a negative response to the control solution.

Forced expiratory volume in one second $\left(\mathrm{FEV}_{1}\right)$ and forced vital capacity (FVC) were measured with a dry wedge spirometer (Vitalograph) at the same time of day after discontinuation of inhaled bronchodilators and abstinence from cigarette smoking for at least six hours. Measurement was repeated until two readings of both $\mathrm{FEV}_{1}$ and FVC were reproducible to within $100 \mathrm{ml}$, and the higher of these was recorded. Patients who were not dyspnoeic on minimal exertion and whose $\mathrm{FEV}_{1}$ was greater than $45 \%$ of the predicted values of Lam et al $^{10}$ underwent bronchial challenge testing by the method of Yan et al. ${ }^{11}$ Inhaled histamine $^{11}$ and methacholine ${ }^{12}$ were given up to a maximum cumulative dose of 7.8 and $6.12 \mu \mathrm{mol}$ respectively. The two tests were performed in random order at the same time of day about a week apart. The dose of histamine $\left(\mathrm{PD}_{20} \mathrm{H}\right)$ and methacholine $\left(\mathrm{PD}_{20} \mathrm{M}\right)$ causing a $20 \%$ fall from the post-saline value was determined. Patients with a $\mathrm{PD}_{20} \mathrm{H}$ of less than 5 $\mu \mathrm{mol}^{1113}$ or an equivalent $\mathrm{PD}_{20} \mathrm{M}$ of less than 6 $\mu \mathrm{mol}^{1214}$ were regarded as having bronchial hyperreactivity. In addition, as a $\mathrm{PD}_{20} \mathrm{H}$ of less than
$7 \cdot 8 \mu \mathrm{mol}$ has been used to define bronchial hyperreactivity in smokers with chronic airflow limitation ${ }^{15}$ on the basis of the method that we used," we also analysed our results using this cut off point.

\section{STATISTICAL ANALYSIS}

Statistical analysis was performed with McNemar's test and Student's $t$ test for spirometric data. Kendall's rank correlation coefficient was used to determine whether there was any relation between $\log P D_{20}$ histamine or methacholine and $\mathrm{FEV}_{1}$ and $\mathrm{FEV}_{1} / \mathrm{VC}$.

\section{Results}

The two groups were well matched for age, sex, and smoking history (table). There were only eight smokers in each group, and most of these were light smokers (less than 10 pack years). There was no difference in the prevalence of asthma, other atopic diseases, family history of atopic disease, or positive skinprick test responses in the two groups. Only one patient with bronchiectasis and none of the controls was diagnosed as having asthma. No patient had a positive skinprick test response to $A$ fumigatus. As a group the patients with bronchiectasis had airflow obstruction, with a reduction in mean (SD) $\mathrm{FEV}_{1}(1.84$ (0.94) 1), FVC (2.44 (0.91) 1), and $\mathrm{FEV}_{1} / \mathrm{FVC}^{\circ}$ (73 (14)) - see table.

Bronchial challenge tests were not undertaken in six patients with bronchiectasis because of dyspnoea and a low FEV $_{1}$. None of the control patients had bron-

Atopic diseases and results of skin tests, baseline spirometry, and bronchial hyperreactivity tests in control subjects and patients with bronchiectasis

\begin{tabular}{|c|c|c|c|}
\hline & $\begin{array}{l}\text { Control } \\
(n=36)\end{array}$ & & $\begin{array}{l}\text { Bronchiectasis } \\
(n=36)\end{array}$ \\
\hline $\begin{array}{l}\text { Sex } \\
\text { Age (mean (SD) y) } \\
\text { No of smokers } \\
\text { Mean pack years }\end{array}$ & $\begin{array}{l}9 \mathrm{M}, 27 \mathrm{~F} \\
43 \cdot 9 \\
8 \\
2 \cdot 6\end{array}$ & & $\begin{array}{l}9 \mathrm{M}, 27 \mathrm{~F} \\
44 \cdot 6 \quad(12 \cdot 8) \\
8 \\
2 \cdot 5\end{array}$ \\
\hline $\begin{array}{l}\text { No of patients with: } \\
\text { asthma } \\
\text { atopic diseases } \\
\text { family history of atopic } \\
\text { diseases } \\
\text { positive skin test responses }\end{array}$ & $\begin{array}{l}0 \\
4 \\
2 \\
5\end{array}$ & & $\begin{array}{l}2 \\
9\end{array}$ \\
\hline $\begin{array}{l}\text { Lung function (mean (SD)) } \\
\text { FEV }(\% \text { predicted) } \\
\text { FVC (\% predicted) } \\
\text { FEV }_{1} / \text { FVC }(\%)\end{array}$ & $\begin{array}{ll}92 & (13) \\
89 & (11) \\
83 & (7)\end{array}$ & $\begin{array}{l}* * * \\
* * * \\
* * *\end{array}$ & $\begin{array}{ll}67 & (20) \\
73 & (13) \\
73 & (14)\end{array}$ \\
\hline $\begin{array}{l}\text { Bronchial hyperreactivity: } \\
\text { to histamine }\left(\mathrm{PD}_{20}<5 \mu \mathrm{mol}\right) \\
\text { to methacholine }\left(\mathrm{PD}_{20}<6\right. \\
\mu \mathrm{mol}) \\
\text { to either or both agents }\end{array}$ & $\begin{array}{l}0 / 30 \\
0 / 30 \\
0 / 30\end{array}$ & $\begin{array}{r}* * \\
* * *\end{array}$ & $\begin{array}{r}7 / 30 \\
6 / 30 \\
10 / 30\end{array}$ \\
\hline
\end{tabular}

${ }^{*} \mathrm{p}<0.05 ;{ }^{* *} \mathrm{p}<0.01 ;{ }^{* * *} \mathrm{p}<0.001$.

$\mathrm{PD}_{20}$ - provocative dose of histamine or methacholine producing a $20 \%$ fall in FEV . 
chial hyperreactivity to histamine or methacholine. Seven patients with bronchiectasis were hyperreactive to histamine ( $p<0.01)$, six to methacholine $(p<$ 0.05 ), and three to both agents, making a total of 10 patients with bronchial hyperreactivity to one or both agents $(p<0.001)$. Of these 10 patients, only three had positive skinprick test responses. When a $\mathbf{P D}_{20}$ histamine of $7.8 \mu \mathrm{mol}$ was used as the cut off point, eight patients in the bronchiectasis group and one patient in the control group had bronchial hyperreactivity $(\mathrm{p}<0.01)$.

No significant correlation was found between $\mathrm{FEV}_{1}$ or $\mathrm{FEV}_{1} / \mathrm{FVC}$ and $\log \mathrm{PD}_{20}$ histamine or methacholine in the patients with bronchiectasis who had bronchial hyperreactivity (figure).

\section{Discussion}

Uncontrolled studies report an apparently high prevalence of asthma (slightly over $20 \%{ }^{23}$ ) and atopy (varying from $30 \%{ }^{16}$ to $42 \%^{2}$ ) in patients with bronchiectasis. This has been used as evidence to support the role of asthma and an allergic diathesis as aetiological factors in bronchiectasis. In the absence of control subjects, however, these prevalence data are difficult to interpret; comparison with published data from normal populations does not take into account differences in diagnostic criteria. More importantly, patients with bronchiectasis are likely to be a highly selected group whose other characteristics may be very different from those of the general population. These points are well illustrated by the study of Murphy et $a l .^{5}$ They found a very high prevalence of atopy in patients with bronchiectasis $(52 \%)$, but this was not

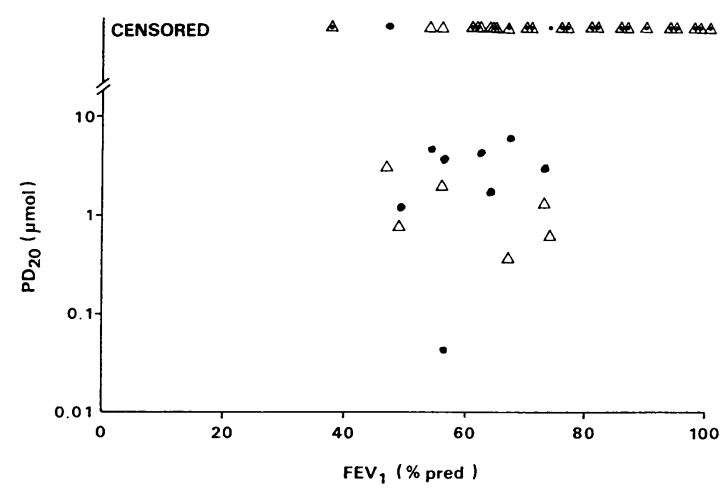

Lack of correlation between FEV, and the degree of bronchial hyperreactivity as measured by log $P D_{20}$ (provocative dose of histamine $(H)$ or methacholine $(M)$ producing a $20 \%$ fall in $\left.F E V_{1}\right)$. Patients whose $P D_{20}$ values were "censored" (that is, above the highest dose given) are shown at the top. $\bullet P D_{20} H$; $\triangle P D_{20} M$. different from the prevalence in normal controls $\stackrel{5}{9}$ matched for age and sex. In this study we also matchedo for smoking habit, a variable known to affect both 흐 atopy ${ }^{67}$ and bronchial reactivity. ${ }^{89}$ This was relatively $\frac{\overline{\bar{F}}}{7}$ easy because most of our patients with bronchiectasis $\stackrel{\Phi}{\Omega}$ were non-smokers or light smokers. After allowing for smoking, we did not find a significant difference in the prevalence of atopy as defined by history or skinprick $\stackrel{\overrightarrow{ }}{\circ}$ testing, though the numbers of patients with a positive $\overrightarrow{\vec{\omega}}$ skin test response in the patients with bronchiectasis $\omega_{\sigma}$ (nine) and the control patients (five) are small. Our $\vec{x}$ findings cast some doubt on the hypothesis that atopy

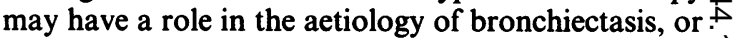
that it may occur as a result of prolonged bronchial $\overrightarrow{\vec{A}}$ suppuration, though larger numbers of subjects are needed to clarify this point.

In this study, bronchial reactivity was measured by $\frac{\text { }}{5}$ the method of Yan et al, "which has been shown to be simple, rapid, and reproducible. ${ }^{113}$ Two different $Z$

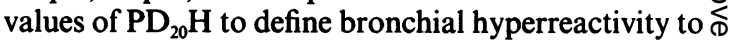
histamine were used for the analyses. The first dose, $5 \frac{3}{\square}$ $\mu \mathrm{mol}$, was chosen because patients with asthma or $\stackrel{\mathbb{\Phi}}{\stackrel{1}{-}}$ wheeze but not atopic controls had a $\mathrm{PD}_{20} \mathrm{H}$ of less $\vec{\oplus}$ than $5 \mu \mathrm{mol}$ in one study. ${ }^{11}$ The higher dose, $7 \cdot 8 \mu \mathrm{mol}$, was chosen because it has been used to define bronchial hyperreactivity in patients with airflow obstruction, ${ }^{15}$ and this was the spirometric pattern found in our patients with bronchiectasis, even though only one $\overline{0}$ patient had asthma. For methacholine a value of $6 \%$ $\mu \mathrm{mol}$ was used to define bronchial hyperreactivity $\varnothing$ because a direct comparison between histamine and $\overrightarrow{\vec{O}}$ methacholine challenge in a community study using $\exists$ the method of Yan et al ${ }^{11}$ showed the two agents to be of similar potency. ${ }^{12}$

Although the prevalence of bronchial hyperreactivity in our patients with bronchiectasis was 응 lower than that reported in uncontrolled studies $\left(50 \%{ }^{24}\right.$ to $\left.69 \%{ }^{3}\right)$, it was significantly higher than that $\frac{0}{5}$ seen in the control subjects. This was true irrespective 3 . of the agent given or the $\mathrm{PD}_{20}$ value used to determine 0 hyperreactivity. Bronchial challenge tests were not performed in six patients with bronchiectasis who had 의 a low $F_{E V}$. If all six patients had been tested and $D$ found to be non-reactive, the difference would still have been significant as only one control patient had $\bar{N}$ bronchial hyperreactivity even when this was defined o in terms of $\mathrm{a} \mathrm{PD}_{20} \mathrm{H}$ of less than $7.8 \mu \mathrm{mol}$.

There are several possible reasons why patients with $\mathrm{N}_{\mathrm{W}}$ bronchiectasis might have a higher prevalence of $\widetilde{O}$ bronchial hyperreactivity. Firstly, an association with atopic diseases, particularly asthma, as suggested by uncontrolled studies, seems unlikely as only a minority $\stackrel{?}{?}$ of patients with bronchiectasis and bronchial 0 hyperreactivity $(3 / 10)$ had positive skin test responses.

Secondly, as a group our patients with bronchiectasis had airflow obstruction, and bronchial $\stackrel{\Phi}{\Phi}$ 
hyperreactivity may reflect the reduction in airway calibre as in smokers. ${ }^{17}$ Although most of our patients were non-smokers, airflow obstruction may still be the mechanism underlying the increased prevalence of bronchial hyperreactivity. There was no correlation, however, between the indices of airflow obstruction and $\log \mathbf{P D}_{20}$ in our patients with bronchiectasis and bronchial hyperreactivity (figure)-although, with the small number of patients and the rather narrow range of values, a significant relationship may have been missed. A preliminary study reported that intensive antibiotic treatment reduced the degree of bronchial hyperreactivity in patients with bronchiectasis without significantly affecting baseline spirometric values. ${ }^{18}$

Thirdly, bronchial hyperreactivity may result from increased access to toxins through infected or inflamed bronchial mucosa, with consequent alteration in smooth muscle tone and autonomic neural regulation. ${ }^{19}$ This is supported by the finding that pulmonary epithelial permeability is increased in patients, with bronchiectasis, ${ }^{20}$ and that bronchial hyperreactivity can be reduced by antibiotic treatment. $^{18}$

Of the 10 patients with bronchiectasis who had bronchial hyperreactivity, four were hyperreactive to histamine only, three were hyperreactive to methacholine only, and three were hyperreactive to both agents. Recent work in both asthmatic ${ }^{21}$ and normal subjects ${ }^{22}$ suggests that inhalation tests with these two agents may measure different phenomena, and the relative lack of overlap in bronchial hyperreactivity to these agents in bronchiectasis is consistent with this view.

Regardless of the mechanism underlying bronchial hyperreactivity in bronchiectasis, the increased prevalence suggests that it may have a role in the pathogenesis of the disease, possibly by impairing clearance mechanisms and thereby contributing to a vicious circle of microbial colonisation and inflammation.

\section{References}

1 Cole P. A new look at the pathogenesis and management of persistent bronchial sepsis: a vicious circle hypothesis and its logical therapeutic connotations. In: Davies RJ, ed. Strategies for the management of chronic bronchial sepsis. Oxford: Medical Publishing Foundation, 1984:1-20.

2 Varpela E, Laitinen LA, Keskinen H, Korhola O. Asthma, allergy and bronchial hyper-reactivity to histamine in patients with bronchiectasis. Clin Allergy 1978;8:273-80.

3 Bahous J, Cartier A, Pineau L, et al. Pulmonary function tests and airway responsiveness to methacholine in chronic bronchiectasis of the adult. Bull Eur Physiopathol Respir 1984;20:375-80.

4 Holmgren A, Ripe E. Airway conductance after inhalation of microaerosols of histamine chloride in healthy subjects and in patients with bronchiectasis before and after operation. Scand J Respir Dis 1973;54:215-22.

5 Murphy MB, Reen DJ, Fitzgerald MX. Atopy, immunological changes, and respiratory function in bronchiectasis. Thorax 1984;34:179-84.

6 Burrows B, Lebowitz MD, Barbee RA. Respiratory disorders and allergy skin-test reactions. Ann Intern Med 1976;84:134-9.

7 Taylor RG, Gross E, Joyce H, Holland F, Pride NB. Smoking, allergy, and their differential white blood cell count. Thorax 1985;10:17-22.

8 Taylor RG, Joyce H, Gross E, Holland F, Pride NB. Bronchial reactivity to inhaled histamine and annual rate of decline in $\mathrm{FEV}_{1}$ in male smokers and exsmokers. Thorax 1985;40:9-16.

9 Burney PGJ, Britton JR, Chinn S, et al. Descriptive epidemiology of bronchial reactivity in an adult population: results from a community study. Thorax 1987;42:38-44.

10 Lam KK, Pang SC, Allan WGL, et al. A survey of ventilatory capacity in Chinese subjects in Hong Kong. Ann Hum Biol 1982;9:459-72.

11 Yan K, Salome C, Woolcock AJ. Rapid method for measurement of bronchial responsiveness. Thorax 1983;38:760-5.

12 Higgins BG, Britton JR, Chinn S, et al. Comparison of histamine and methacholine for use in bronchial challenge tests in community studies. Thorax 1988;43: 605-10.

13 Britton J, Mortagy A, Tattersfield A. Histamine challenge testing: comparison of three methods. Thorax 1986;41:128-32.

14 Woolcock AJ. Expression of results of airway hyperresponsiveness. In: Hargreave FE, Woolcock AJ, eds. Airway responsiveness: measurement and interpretation. Ontario: Astra, 1985:80-5.

15 Du Toit J, Woolcock AJ, Salome CM, Sundrum R, Black JL. Characteristics of bronchial hyperresponsiveness in smokers with chronic air-flow limitation. Am Rev Respir Dis 1986;134:498-501.

16 Hilton AM, Doyle L. Immunological abnormalities in bronchiectasis with chronic bronchial suppuration. $\mathrm{Br}$ J Dis Chest 1978;72:207-16.

17 Ramsdale EH, Morris MM, Roberts RS, Hargreave FE. Bronchial responsiveness to methacholine in chronic bronchitis: relationship to airflow obstruction and cold air responsiveness. Thorax 1984;39:912-8.

18 Kelly CA, Stenton C, Gould K, Hendrick DJ, Walters EH. The effect of high dose amoxycillin on bronchial responsiveness and symptoms in patients with bronchiectasis [abstract]. Am Rev Respir Dis 1987; 135:A269.

19 Boushey HA, Holtzman MJ, Sheller JR, Nadel JA. Bronchial hyperreactivity. Am Rev Respir Dis 1980; 121:389-413.

20 Chan TB, Arm JP, Anderson J, Eiser NM. PuImonary epithelial permeability in bronchiectasis. Br J Dis Chest 1988;82:56-63.

21 Connolly MJ, Avery AJ, Walters EH, Hendrick DJ. The relationship between bronchial responsiveness to methacholine and bronchial responsiveness to histamine in asthmatic subjects. Pulm Pharmacol 1988;1: 53-8.

22 Sekizawa K, Yanai M, Shimizu Y, Sasaki H, Takishima T. Serial distribution of bronchoconstriction in normal subjects. Am Rev Respir Dis 1988;137:1312-6. 